\title{
Corticotropin-Releasing Hormone As the Homeostatic Rheostat of Feto-Maternal Symbiosis and Developmental Programming In Utero and Neonatal Life
}

OPEN ACCESS

Edited by:

Hubert Vaudry,

University of Rouen, France

Reviewed by:

Denis Richard,

Laval University, Canada

James A. Carr,

Texas Tech University,

United States

${ }^{*}$ Correspondence:

Dimitris K. Grammatopoulos

d.grammatopoulos@

warwick.ac.uk

${ }^{\dagger}$ Equal first co-authors.

Specialty section: This article was submitted to Neuroendocrine Science,

a section of the journal

Frontiers in Endocrinology

Received: 02 April 2017 Accepted: 23 June 2017

Published: 11 July 2017

Citation: Alcántara-Alonso V, Panetta $P$, de Gortari $P$ and

Grammatopoulos DK (2017) Corticotropin-Releasing Hormone As the Homeostatic Rheostat of

Feto-Maternal Symbiosis and Developmental Programming

In Utero and Neonatal Life.

Front. Endocrinol. 8:161. doi: 10.3389/fendo.2017.00161

\section{Viridiana Alcántara-Alonso ${ }^{1,2 t}$, Pamela Panetta ${ }^{1 \dagger}$, Patricia de Gortari ${ }^{2}$ and Dimitris K. Grammatopoulos ${ }^{1,3 *}$}

\begin{abstract}
${ }^{1}$ Translational Medicine, Warwick Medical School, Coventry, United Kingdom, ${ }^{2}$ Laboratory of Molecular Neurophysiology, Department of Neurosciences Research, National Institute of Psychiatry Ramón de la Fuente Muñiz, Mexico City, Mexico, ${ }^{3}$ Clinical Biochemistry, Coventry and Warwickshire Pathology Service, UHCW NHS Trust, Coventry, United Kingdom
\end{abstract}

A balanced interaction between the homeostatic mechanisms of mother and the developing organism during pregnancy and in early neonatal life is essential in order to ensure optimal fetal development, ability to respond to various external and internal challenges, protection from adverse programming, and safeguard maternal care availability after parturition. In the majority of pregnancies, this relationship is highly effective resulting in successful outcomes. However, in a number of pathological settings, perturbations of the maternal homeostasis disrupt this symbiosis and initiate adaptive responses with unpredictable outcomes for the fetus or even the neonate. This may lead to development of pathological phenotypes arising from developmental reprogramming involving interaction of genetic, epigenetic, and environmental-driven pathways, sometimes with acute consequences (e.g., growth impairment) and sometimes delayed (e.g., enhanced susceptibility to disease) that last well into adulthood. Most of these adaptive mechanisms are activated and controlled by hormones of the hypothalamo-pituitary adrenal axis under the influence of placental steroid and peptide hormones. In particular, the hypothalamic peptide corticotropin-releasing hormone $(\mathrm{CRH})$ plays a key role in feto-maternal communication by orchestrating and integrating a series of neuroendocrine, immune, metabolic, and behavioral responses. $\mathrm{CRH}$ also regulates neural networks involved in maternal behavior and this determines efficiency of maternal care and neonate interactions. This review will summarize our current understanding of $\mathrm{CRH}$ actions during the perinatal period, focusing on the physiological roles for both mother and offspring and also how external challenges can alter $\mathrm{CRH}$ actions and potentially impact on fetus/neonate health.

Keywords: corticotropin-releasing hormone, placenta, hypothalamo-pituitary adrenal axis, homeostasis, glucocorticoids, allostasis, neurodevelopment, metabolism

\section{INTRODUCTION}

The prenatal period represents an immensely challenging phase for the maternal physiology, as it requires continuous adaptive changes to accommodate functional impact of new organs such as the placenta and also increasing and variable demands in response to the new organism's growth, expansion, and development (1). These changes are also important as they prepare the mother for labor 
and delivery and later maternal care. A selective redistribution of the fuels used by mother and fetus allows the pregnant mother to preferentially use fat for fuel, preserving the available glucose and amino acids for the fetus and minimizing protein catabolism. This inter-dependent sharing of metabolic resources and nutrient energy substrate availability might influence length of gestation and pregnancy outcomes. In this context, preterm onset of labor may represent a maternal adaptation to limit the metabolic cost of a pregnancy threatened by adverse conditions, or alternatively a fetal adaptation to an unfavorable intrauterine environment.

The intrauterine conditions in which the developing fetus grows have an important role in regulating the function and preserving integrity of its physiological systems later in life. Studies confirm that environmental perturbations altering the intrauterine availability of nutrients, oxygen, and hormones program fetal development and ultimately offspring physiological outcomes (2-11); thus, the ability to mount appropriate adaptive responses and counteract adversity is essential for pregnancy success and to minimize the cost on organism's health. Lessons from mammalian evolutionary biology and current developmental plasticity concepts suggest that a key player in these pregnancy-induced changes is the hypothalamo-pituitary adrenal (HPA) axis, which regulates central and peripheral homeostatic adaptive responses to stress $(12,13)$. The HPA axis finely tunes the symbiotic relationship of mother and developing fetus and also determines length of gestation and timing of onset of mammalian parturition. Development of such coordinated responses is crucial since the developing fetus decodes and integrates environmental signals partly via activation of the same biological systems that in mature organisms mediate adaptation and central and peripheral biological and behavioral responses to endogenous and exogenous stressors (e.g., the maternal-placental-fetal neuroendocrine systems). Emerging data also identify the HPA axis as a key player in the development of the progeny especially the first few months outside the intrauterine environment, a critical period for development with considerable interactions between genetics and environment. However, this asymmetric interaction between two organisms in different developmental stages that requires continuous adjustment is poorly understood. This review will examine the current evidence on hormonal responses of the HPA axis initiated by the hypothalamic peptide corticotropin-releasing hormone (CRH) and the mechanisms involved in establishing an effective mother-progeny symbiosis in the prenatal environment and later during the early neonatal period, the effects of which shape the organism's health and behavior throughout life.

\section{MATERNAL HPA AXIS AND CRH}

Pregnancy is characterized by dramatic changes in the fetomaternal stress-hormonal system that impacts on the maternal HPA axis function. The anthropoid primate placenta appears to be unique in producing $\mathrm{CRH}$. There are at least two patterns of secretion of placental CRH (pCRH) across gestation among anthropoids. Certain monkeys (Papio and Callithrix) have an early-to-mid gestational peak, followed by a steady decline to a plateau level, with a possible further rise near parturition. By contrast, humans and great apes placenta secretes large quantities of pCRH into the maternal bloodstream during the second and third trimesters of pregnancy and this exponential rise peaks at parturition (14-17). Interestingly, unlike the hypothalamic peptide, $\mathrm{pCRH}$ secretion is augmented by cortisol, thus providing a unique positive feedback loop extension to the feto-maternal stress axis that sustains high levels of CRH secretion throughout pregnancy (Figure 1A). Elevated maternal cortisol at 15 weeks of gestation predicts elevated CRH at 31 weeks, suggesting that elevated cortisol early in pregnancy can exert priming effects on fetal/pCRH system (18).

Both human and rodent feto-maternal tissues have "in-built" defense mechanisms that protect the fetus from exposure to high levels of maternal glucocorticoids and detrimental effects of programming. For example, failure of the $11 \beta$-hydroxysteroid dehydrogenase 2 (11 $\beta$-HSD2) barrier to prevent fetal overexposure is associated with pregnancy complications such as lower birth weight and shorter gestation at delivery (19-21) as well as long-term consequences for the offspring, including resetting of the HPA axis and susceptibility to neurodevelopmental problems and cardio-metabolic disease (22-26).

As pregnancy progresses toward term, maternal hypothalamic production of CRH is downregulated and, thus, the responsiveness of the maternal HPA axis to both physiological and psychological stress is attenuated, a critical adaptation event that provides protection for mother and fetus from the effects of adversity (27-30). It is conceivable that women who fail to show the expected decrease in HPA reactivity to stress and anxiety are at increased risk of complications such as for preterm delivery (31-33), although assessment of anxiety during pregnancy is challenging and can be difficult to distinguish between "normal" pregnancy symptoms, which are common during pregnancy, and atypical somatic complaints such as fatigue, loss of energy, appetite, and sleep changes, which may be related to depression or anxiety.

In the postpartum period, following delivery of the placenta and a sharp drop in pCRH and steroid hormone levels, maternal plasma cortisol levels fall and the function of the mother's HPA axis and most homeostatic systems gradually return to its prepregnant state. Due the prolonged effects of glucocorticoids, the HPA axis is relatively hypo-responsive to dexamethasone suppression for up to 3 weeks postpartum, and recovery of CRH secretion is evident by 12 weeks postpartum $(34,35)$. Altered HPA responses to pregnancy may influence later maternal mental health and mood disturbances, ultimately compromising quality of maternal care in the postpartum period (36-38).

\section{CRH-HPA AXIS AND METABOLIC FUEL DISTRIBUTION BETWEEN MOTHER AND FETUS}

To meet the increased energy demands of mother and fetus, food intake increases in pregnancy by resetting central appetitecontrol mechanisms (39), involving development of central leptin resistance and differential regulation of central actions of other orexigenic and anorexigenic hormones and neurosteroids that shift the balance toward increased appetite, food intake and 
A

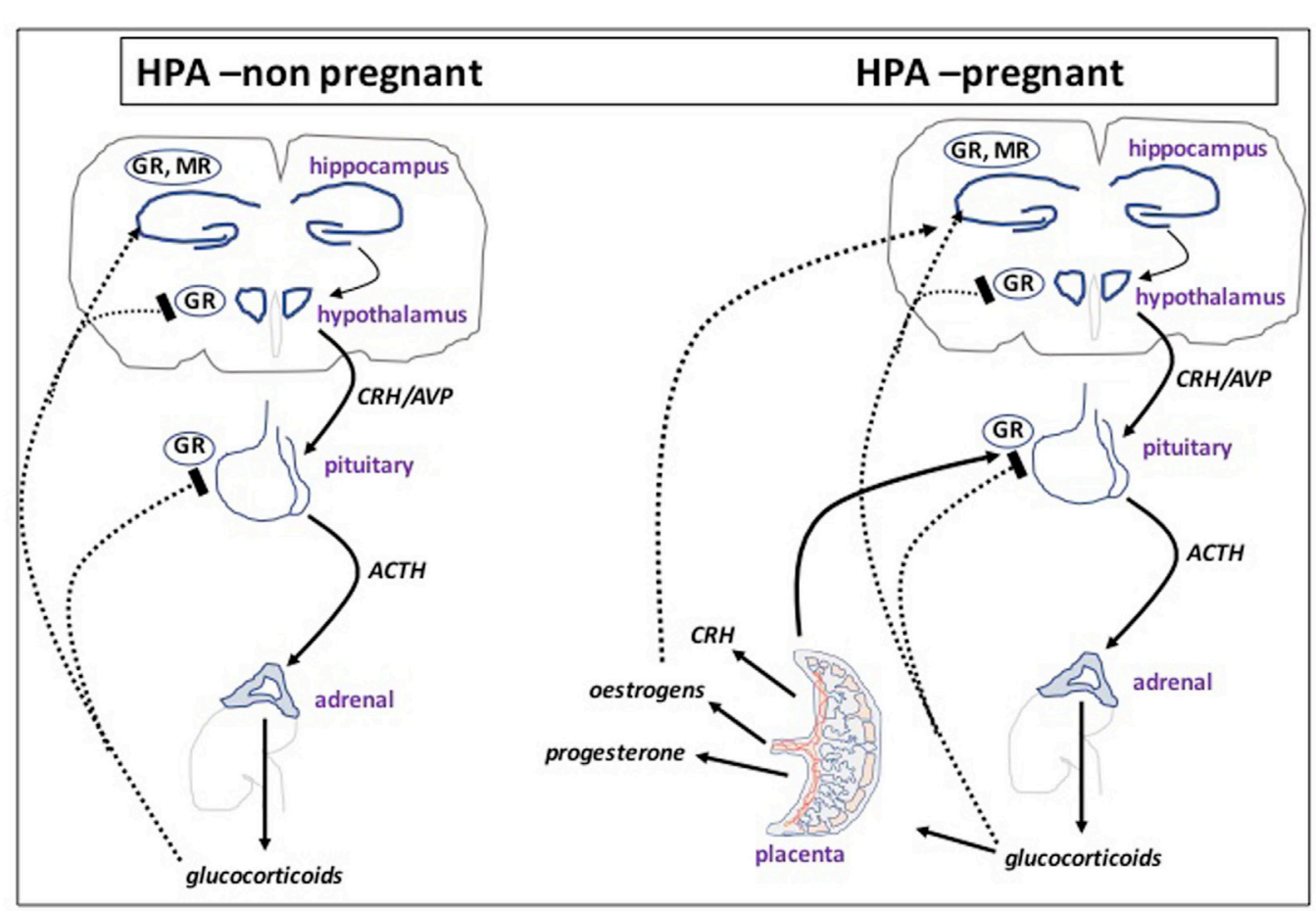

B

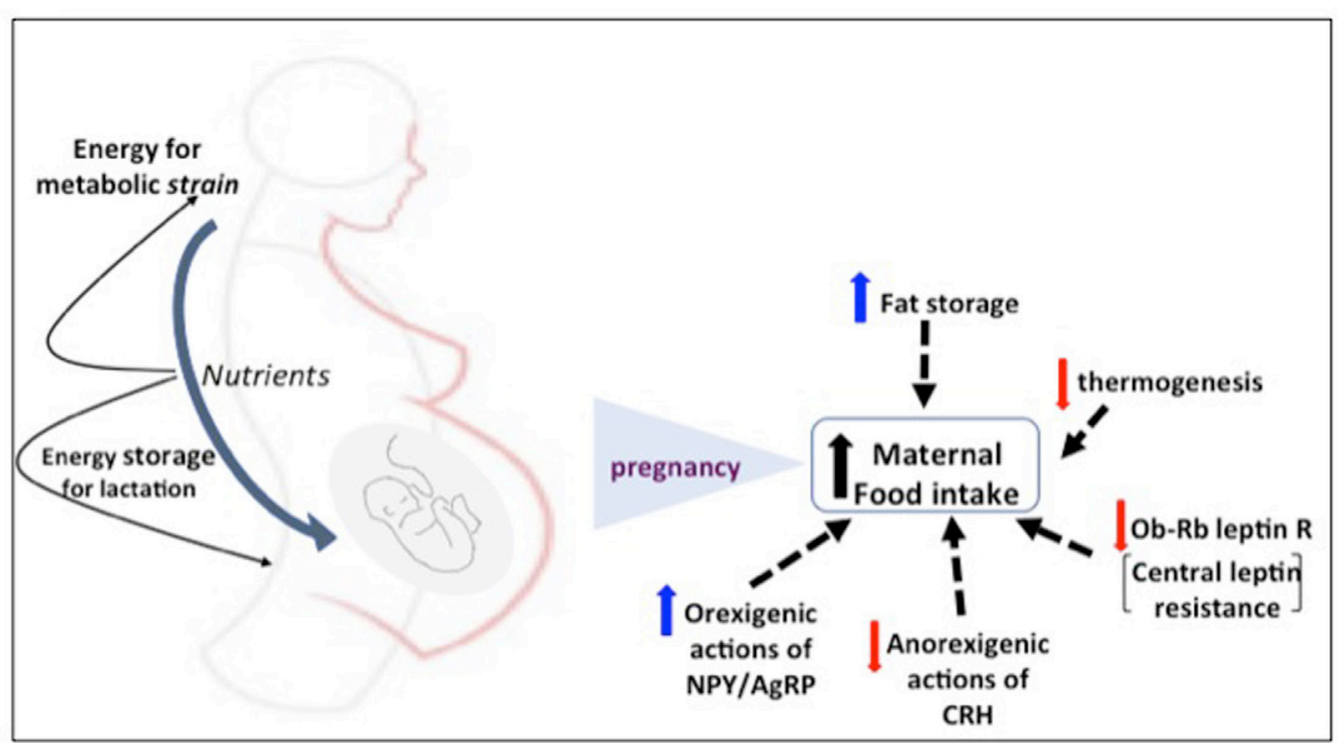

FIGURE 1 | (A) The first step of mammalian hypothalamo-pituitary adrenal (HPA) axis activation in response to psychological or physical stressors involves activation of neurosecretory corticotropin-releasing hormone $(\mathrm{CRH})$ neurons in the hypothalamic paraventricular nucleus. $\mathrm{CRH}$ and AVP released into the hypophysial portal blood system stimulate adrenocorticotropic hormone (ACTH) release from anterior pituitary corticotrophs and, in turn, the adrenal to secrete glucocorticoids (corticosterone in rodents) into the bloodstream. Cortisol tightly controls HPA activity by feeding back to glucocorticoid receptors (GR) and mineralocorticoid receptors (MR) in the pituitary and hypothalamus to turn-off CRH release and its own secretion. In humans and higher primate pregnancy, placenta secretes large quantities of $\mathrm{CRH}$ into the maternal bloodstream during the second and third trimesters of pregnancy. Placental $\mathrm{CRH}$ secretion is augmented by cortisol, thus providing a unique positive feedback loop extension to the feto-maternal stress axis that sustains high levels of $\mathrm{CRH}$ secretion throughout pregnancy. (B) In response to increased energy demands of mother and fetus, food intake increases in pregnancy by resetting central appetite-control mechanisms. A key molecular event appears to be altered leptin signaling and development of central leptin resistance. This is primarily due to decreased expression of the Ob-Rb leptin receptor in the ventromedial hypothalamus and reduced signaling activity despite increased concentration of circulating leptin as a result of expansion of the adipose tissue with contribution from placental secretion. This is coupled with differential regulation of central actions of other orexigenic and anorexigenic hormones and neurosteroids, such as CRH, NPY and AgRP, progesterone, and allopregnanolone that shift the balance toward increased appetite and food intake and fat storage and decreased thermogenesis. These mechanisms ensure that there are sufficient nutrients for the fetus, sufficient energy for the extra metabolic strain on the mother, and a surplus of energy that can be stored as fat in preparation for lactation. 
fat storage, and decreased thermogenesis $(39,40)$ (Figure 1B). These mechanisms ensure that there are sufficient nutrients for the fetus, sufficient energy for the extra metabolic strain on the mother, and a surplus of stored energy. Changes in maternal metabolic state are directly transmitted to the fetus: for example, maternal hyperglycemia in pregnant women induces hyperglycemia and elevated insulin levels in the fetus, thus increasing the risk for complications in infancy and later life (41). Moreover, Barker and colleagues (42) established that derangement of fetal growth trajectories and neonatal development are directly linked to maternal nutritional status, suggesting that both intra- and extra-uterine environment work as a continuum to determine the metabolic status of the progeny.

Homeostatic challenges such as prenatal maternal stress can program offspring obesity and metabolic disease risk in adulthood (43-46). This involves pathogenic mechanisms reorganizing immature neural pathways at the hypothalamus (47-49). In this pathological setting, a possible indirect role for $\mathrm{CRH}$ in programming homeostasis of energy balance and metabolism at adulthood has been suggested since changes in growth trajectories associated with altered pCRH levels and reduced fetal growth and size at birth are predictors of childhood and adult adiposity (50). In addition, a positive association has been identified between elevated $\mathrm{CRH}$ at 30 weeks of gestation and a phenotypic pattern of an early small body size followed by a rapid catch-up growth (51), previously associated with early development of adiposity and insulin resistance (52). Higher circulating levels of CRH also correlate with increased central adiposity (53) and increased levels of adiponectin probably as a compensatory mechanism to improve insulin sensitivity in childhood (54).

Maternal obesity, another type of metabolic challenge, increases risk of fetus developing obesity, insulin resistance, and metabolic syndrome $(49,55-57)$. It is possible that during maternal obesity, CRH, up-regulated by maternal cortisol, might act as an autocrine/paracrine regulator to increase glucose uptake and facilitate transfer from the mother to the fetus through the upregulation of GLUT1 in the placenta (58). Moreover, CRH could interact with placental and peripheral systems to enhance the production of pro-inflammatory cytokines and pro-inflammatory factors that can reach the fetus. Enhanced secretion from the placenta of cytokines and adipokines are linked to a number of pathological states, including gestational diabetes, hypertension, and intrauterine growth restriction (59).

\section{CRH-HPA AXIS IN FETAL NEURODEVELOPMENT}

Pregnancies complicated by pathological perturbations leading to poor fetal outcomes, including premature labor, hypertension, and intrauterine fetal growth retardation (IUGR) are associated with increased $\mathrm{CRH}$ production by the placenta and secretion into maternal blood (60-63). The diverse placental signaling mechanisms regulated by $\mathrm{CRH}$ suggest that elevated $\mathrm{CRH}$ controls the placental "surveillance and response" system so that the fetus can detect threats to survival and adjust its developmental trajectory (64-67) (Figure 2A). When stress signals (e.g., cortisol) from the maternal environment are detected by the fetoplacental unit, the "placental clock" may adapt by altering rate of synthesis of the "master" stress hormone, CRH. The rapid increase in circulating CRH might initiate mechanisms to regulate myometrial contractile machinery and the onset of labor $(68,69)$. In parallel, fetal developmental trajectories are adjusted to accelerate maturation of critical organs such as modification of its nervous system to ensure survival in a potentially hostile environment $(70,71)$.

Evidence point toward delayed fetal maturation and impaired cognitive performance during infancy resulting in decreased brain volume in areas associated with range of cognitive functions, including learning and memory in children (72). These fetal neurobiological adjustments on brain development might involve direct effects of $\mathrm{CRH}$, which can exert neurotoxic effects on hippocampal neurons especially in the immature hippocampus (73-75). In addition, elevated concentrations of CRH may affect directly the developing brain through changes in neuronal sensitivity to $\mathrm{CRH}$ actions especially in amygdala and hippocampus, two key regions involved in mediating the central stress response and integrating information regarding "emotional" or "cognitive" stress $(76,77)$.

The impairment in neurodevelopment associated with altered levels of CRH can be detected early during in utero life. Studies assessing neurological integrity during pregnancy suggest that exposure to lower levels of CRH early in gestation may be associated with greater maturity of the fetal central nervous system and accelerated neurological development (70). Moreover, fetal exposure to increased levels of maternal cortisol at 15 weeks and at 19 weeks of gestation and increased levels of $\mathrm{CRH}$ at 31 weeks gestation are associated with a significant decrease in newborn physical and neuromuscular maturation. These neonatal measures of maturation reflect altered neurological development detected with magnetic resonance imaging in newborns, including basal ganglia and white matter lesions, as well as motor abnormalities that persist in early childhood (71).

\section{CRH-HPA AXIS AND THE INTERACTION BETWEEN MOTHER AND THE NEONATE}

After parturition, the connection between neonate and mother shifts to a new physiological equilibrium from a complete physiological dependence to one where two separate individual organisms are in close physical and behavioral contact; this biological relationship can also be influenced by environmental adversity. Young mammals still depend upon the mother for nutrition and physical stimulation as they mature toward complete nutritional independence. Any disruption of the maternal-neonate postnatal interaction by early life events can also induce programming responses with long-lasting consequences. The $\mathrm{CRH}$ system is recognized as key for coordinating or even directly inducing adaptations that support the organism to defend against stressful situations such as deterioration of quality of maternal care to maintain homeostasis and survival. However, the immaturity of the CRH system in the newborn makes it vulnerable and susceptible to develop functional abnormalities and ultimately disease later in life (78-80). 


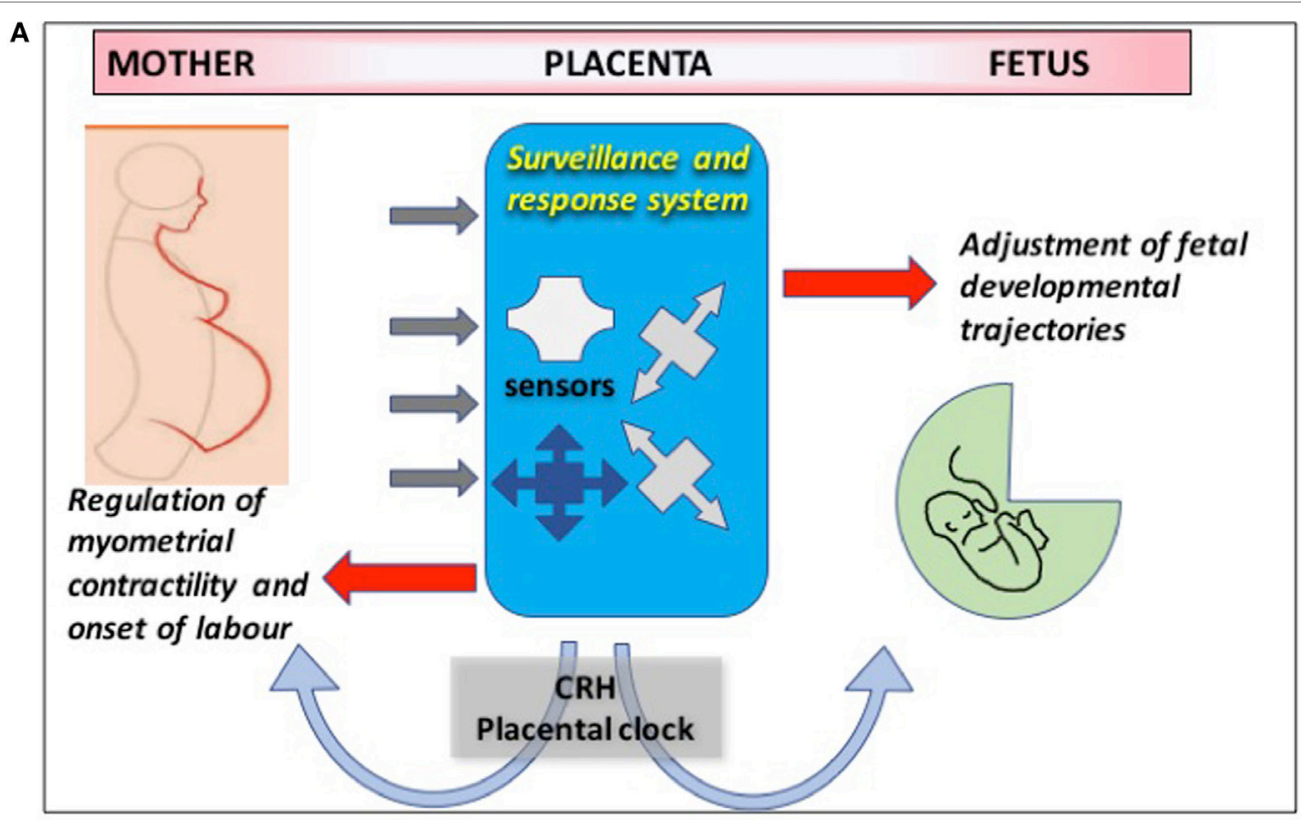

B

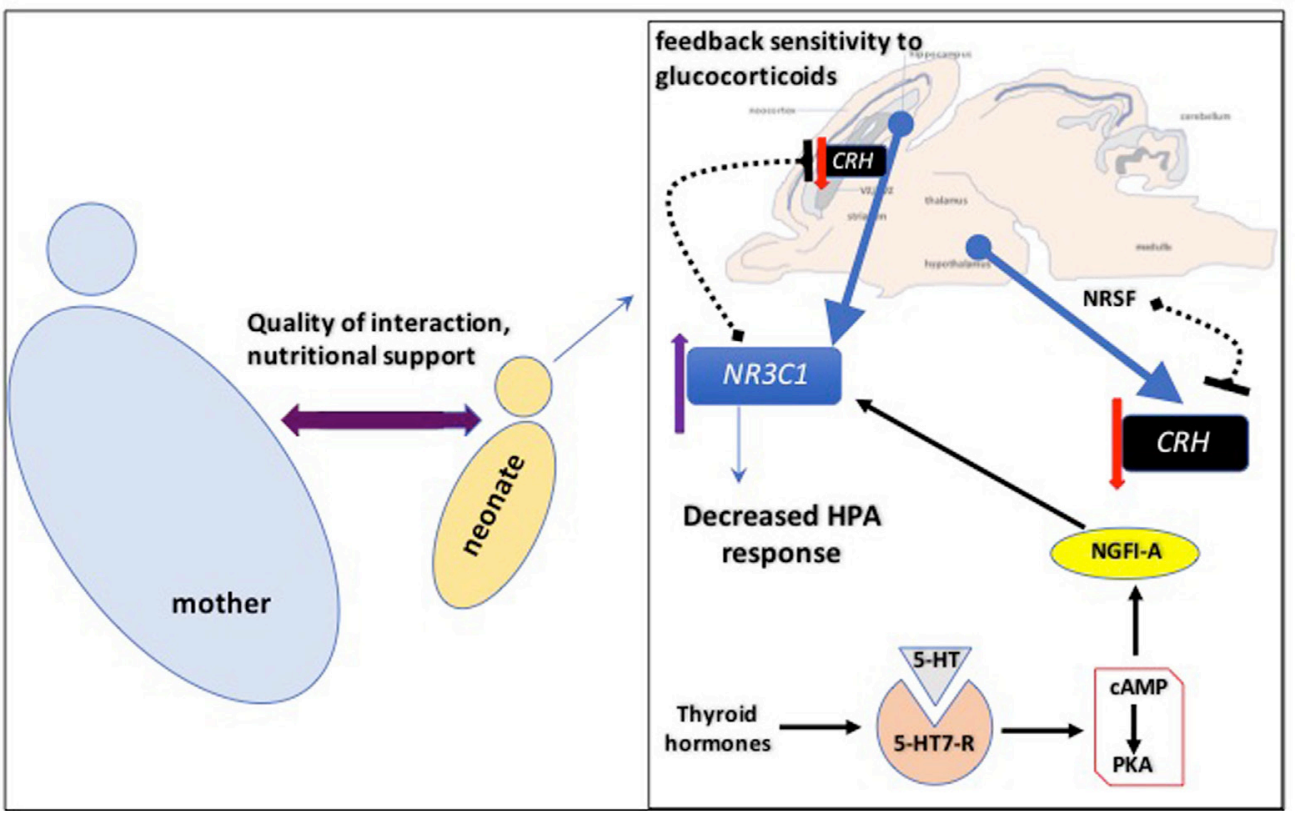

FIGURE 2 | (A) Corticotropin-releasing hormone (CRH) controls the placental "surveillance and response" system so that the fetus can detect threats to survival and adjust its developmental trajectory. The placenta employs an intricate network of sensors to decode signals from the maternal environment and prepare the fetus for postnatal survival. Disruption of these sensors might have detrimental effects on fetal neurodevelopment. The "CRH placental clock" might be part of this surveillance and response system: when stress signals such as cortisol from the maternal environment are detected by the fetal/placental unit, the "placental clock" may adapt by altering rate of synthesis of the "master" stress hormone, $\mathrm{CRH}$. The rapid increase in circulating $\mathrm{CRH}$ might initiate mechanisms targeting maternal tissues to regulate myometrial contractile machinery and the onset of labor. In parallel, fetal developmental trajectories are adjusted to accelerate maturation of critical organs such as modification of its nervous system to ensure survival in a potentially hostile environment. (B) Maternal behaviors resulting in decreased hypothalamo-pituitary adrenal (HPA) axis response to stress in adulthood are most likely driven by enhanced feedback sensitivity of CRH to glucocorticoids in the hippocampus. This involves epigenetic modifications of $N R 3 C 1$, the gene encoding glucocorticoid receptors, in the brain increasing its mRNA expression via mechanisms that promote binding of the transcription factor nerve growth factor-inducible factor A (NGFI-A). This interaction involves a thyroid-hormone-dependent increase in serotonin (5-HT) activity at 5-HT7 receptors and the subsequent activation of cyclic adenosine monophosphate (cAMP) and protein kinase A (PKA) pathway. Hippocampal $\mathrm{CRH}$ gene expression is also regulated by maternal care and early life stress through similar epigenetic mechanisms. Similarly, increased histone $\mathrm{H} 3$ acetylation and decreased cytosine methylation in the promoter region of $\mathrm{CRH}$ gene in hippocampal CA1 layer promote mRNA expression of the neuropeptide. One potential mechanism that enables positive environmental signals (induced by augmented maternal care) to influence transcription of the $\mathrm{CRH}$ gene in the offspring hypothalamus involves increased hypothalamic levels of the repressor neuron-restrictive silencer factor (NRSF). NRSF represses the transcription of the $\mathrm{CRH}$ gene by binding in the regulatory region of the $\mathrm{CRH}$ gene, an epigenetic regulation that persists into adulthood. 
In rodents, the period of HPA axis immaturity from birth to the second postnatal week is characterized by a stress hyporesponsive period. This has been attributed mainly to glucocorticoid receptors (GR): reduced functionality in the hypothalamic paraventricular nucleus (PVN) would enhance expression of CRH $(81,82)$, although enhanced GR negative feedback in the pituitary, would diminish stress response of newborn animals (83). Similar diminished stress response is observed in humans during the first year of life (84) and in non-human primates that also respond to quality of maternal care (85).

Lactation and milk infusion can have beneficial effects on HPA axis activity and maintain low concentrations of circulating corticosterone even in the mother's absence (80). Acquisition of nutrients during lactation represents a direct bond between infant and mother in early life. Milk composition can also affect various homeostatic parameters, such as growth rate, metabolism, neurodevelopment, and stress reactivity. It is considered as the main vehicle by which glucocorticoids pass from the mother to the offspring $(86,87)$ and influence the expression of neonatal $\mathrm{CRH}$ and ultimately the normal maturation of the HPA axis (88). Thus, maternal diet plays a key role in the type of nutrients that are transferred to the neonate and HPA biological settings; consumption of a high fat diet during pregnancy and/or lactation periods increases not only the fat content of the milk but also the corticosterone plasma levels in dams. This would program the offspring not only toward overweight in the adulthood but also increases corticosterone circulating levels and the risk of metabolic syndrome (89).

\section{CRH AND METABOLIC ADJUSTMENTS UNDER POSTNATAL STRESS}

Disruption of maternal care promotes distinct endocrine, metabolic, and behavioral phenotypic responses in the offspring. Emerging pieces of evidence suggest an early life stress-induced interaction between the HPA axis and energy balance mechanisms leading to deranged metabolic profile later in life associated with insulin resistance. An interesting hypothesis identifies liver $11 \beta$-HSD1-HPA axis interactions as a potential pathway in earlylife stress-mediated metabolic disturbances, particularly insulin sensitivity, glucose metabolism and lipid synthesis, and mobilization possibly involving changes in glucocorticoid metabolism and signaling (90).

Maternal behaviors resulting in highly nurtured pups that exhibit decreased HPA axis response to stress in adulthood are most likely driven by enhanced feedback sensitivity to glucocorticoids in the hippocampus. This likely involves epigenetic modifications of $N R 3 C 1$, the gene encoding GR, in the brain increasing its mRNA expression $(91,92)$ (Figure 2B). It is proposed that a global epigenetic signature of early life experience is maintained across species and centered around GR gene regulation, which targets specific regulatory regions such as gene promoters, particularly those of the protocadherin $\alpha, \beta$, and $\gamma$ gene families (93).

By contrast, a disrupted maternal care during the hyporesponsive period could also impact gene expression by opposing epigenetic mechanisms $(79,94)$. Postmortem studies on human brain samples from suicide victims with reported childhood neglect/abuse support this theory and showed that methylation of the NR3C1 promoter is increased and expression of GR reduced in hippocampal tissue (95).

Hypothalamic CRH gene expression is also regulated by maternal care and early life stress through similar epigenetic mechanisms (96). Similarly, increased histone H3 acetylation and decreased cytosine methylation in the promoter region of CRH gene in hippocampal CA1 layer promote mRNA expression of the neuropeptide induced by the same stress paradigm (97). Interestingly, environmental enrichment after weaning reverses both the epigenetic upregulation of the $\mathrm{CRH}$ expression and the hippocampal synaptic dysfunction of maternally separated animals (97), indicating epigenetic flexibility in this system influenced also by positive stimulus. One potential mechanism that enables positive environmental signals to influence transcription of the $\mathrm{CRH}$ gene in the offspring hypothalamus involves the repressor neuron-restrictive silencer factor (98).

A number of maternal deprivation experimental protocols that disrupt maternal-offspring interaction especially during the lactation period and increase the stressful environment of the pups identified altered functionality of the CRH system. These are associated with long-lasting increases in food intake, body weight, and metabolic syndrome risk. Molecular defects identified include decreased expression of CRH-R2 in the ventromedial hypothalamus (VMH) especially in the absence of sensory stimuli (99), a receptor subtype that elicits the anorexigenic effect of CRH and urocortins (100). Lack of maternal care, milk ingestion and hypothermia, lead to increased corticosterone levels (101, 102) and chronically alter the glucocorticoid feedback, maintaining increased synthesis and cerebro-spinal fluid (CSF) concentrations of $\mathrm{CRH}$, as well as basal corticosterone concentrations until adulthood $(103,104)$. In some examples of impact of neonatal stress in adulthood, adult male offspring show increased $\mathrm{CRH}$ expression in the hypothalamus and hippocampus, memory deficits, dendritic atrophy, and altered adult hippocampal neurogenesis (105), whereas female adults show increased corticosterone release in response to stress, anxiety, behavior, and preference to eat palatable food compared to control rats (106). Such a hyperphagic behavior of animals experiencing maternal separation (MS) early in life could be caused by increased hypothalamic expression of NPY (107) associated with a decreased signaling of CRH-R2 receptors in the PVN. Adult MS animals show decreased behavioral and biochemical response to an intraPVN injection of exogenous urocortin 2, suggesting its altered functionality might be attributable to a chronic stress exposure (108). The levels of CRH-R2 in the VMH are under the control of maternal stimuli in early postnatal life (99), thus, maternal care-driven mechanisms might influence CRH-R2 function in PVN. Similar to animal findings, increased basal glucocorticoid levels, altered glucocorticoid feedback and presence of higher CSF concentrations of CRH are observed in humans subjected to emotional neglect and particularly to parental stress during childhood (109-111). This hyperactivation of the HPA axis system promotes the development of obesity and metabolic syndrome $(112,113)$ because of the influence of glucocorticoids on orexigenic hypothalamic signals, predominantly stimulating the 
drive for hypercaloric foods $(112,114,115)$. Also, environmental adversity associated with low socioeconomic status during childhood is a predictor of metabolic risk factors, including increased body mass index and altered insulin sensitivity in adults with parental loss and neglect during infancy; all associated with higher basal cortisol levels $(79,115)$.

\section{CONCLUSION}

Interactions of the fetus/neonate with the mother are emerging as critical for organism's development that determines resilience to adversity across the lifespan. In the developing organism, $\mathrm{CRH}$ and the HPA axis appear particularly sensitive to exposure to signals from the maternal environment, either physical or behavioral responses to stress or disease. Their ability to influence the activity of molecular switches and mechanisms with key roles in developmental outcomes identifies a critical need to maintain tight homeostatic control of these mechanisms since deranged adaptive responses have devastating consequences either directly or through permanent programming that influence disease susceptibility. Recognizing and characterizing these

\section{REFERENCES}

1. Soma-Pillay P, Nelson-Piercy C, Tolppanen H, Mebazaa A. Physiological changes in pregnancy. Cardiovasc JAfr (2016) 27:89-94. doi:10.5830/ CVJA-2016-021

2. Symonds ME, Gardner DS. Experimental evidence for early nutritional programming of later health in animals. Curr Opin Clin Nutr Metab Care (2006) 9:278-83. doi:10.1097/01.mco.0000222112.46042.19

3. Vickers MH. Early life nutrition, epigenetics and programming of later life disease. Nutrients (2014) 6:2165-78. doi:10.3390/nu6062165

4. Purcell RH, Sun B, Pass LL, Power ML, Moran TH, Tamashiro KL. Maternal stress and high-fat diet effect on maternal behavior, milk composition, and pup ingestive behavior. Physiol Behav (2011) 104:474-9. doi:10.1016/j. physbeh.2011.05.012

5. Sun B, Purcell RH, Terrillion CE, Yan J, Moran TH, Tamashiro KL. Maternal high-fat diet during gestation or suckling differentially affects offspring leptin sensitivity and obesity. Diabetes (2012) 61:2833-41. doi:10.2337/ db11-0957

6. Capron LE, Glover V, Pearson RM, Evans J, O'Connor TG, Stein A, et al. Associations of maternal and paternal antenatal mood with offspring anxiety disorder at age 18 years. J Affect Disord (2015) 187:20-6. doi:10.1016/j. jad.2015.08.012

7. Cirulli F, Berry A, Alleva E. Early disruption of the mother-infant relationship: effects on brain plasticity and implications for psychopathology. Neurosci Biobehav Rev (2003) 27:73-82. doi:10.1016/S0149-7634(03) 00010-1

8. Cottrell EC, Seckl JR. Prenatal stress, glucocorticoids and the programming of adult disease. Front Behav Neurosci (2009) 3:19. doi:10.3389/ neuro.08.019.2009

9. Dimasuay KG, Boeuf P, Powell TL, Jansson T. Placental responses to changes in the maternal environment determine fetal growth. Front Physiol (2016) 7:12. doi:10.3389/fphys.2016.00012

10. Sferruzzi-Perri AN, Camm EJ. The programming power of the placenta. Front Physiol (2016) 7:33. doi:10.3389/fphys.2016.00033

11. Cirulli F. Interactions between early life stress and metabolic stress in programming of mental and metabolic health. Curr Opin Behav Sci (2017) 14:65-71. doi:10.1016/j.cobeha.2016.12.009

12. Bale TL, Vale WW. CRF and CRF receptors: role in stress responsivity and other behaviors. Annu Rev Pharmacol Toxicol (2004) 44:525-57. doi:10.1146/ annurev.pharmtox.44.101802.121410
HPA adaptations (or mal-adaptations) offer a promising strategy for development of novel preventative or therapeutic approaches.

\section{AUTHOR CONTRIBUTIONS}

All authors (VA-A, PP, PG, and DG) participated in the idea development and equally contributed in the writing up of the manuscript and approved the final version.

\section{ACKNOWLEDGMENTS}

The authors would like to thank colleagues within the Translational Medicine Research group at WMS for useful discussions and input in the development of the manuscript.

\section{FUNDING}

VA-A is a Visiting scientist at the University of Warwick funded by the Mexican Council for Science and Technology (CONACyT). $\mathrm{PP}$ is a University of Warwick postgraduate student funded by a WCPRS/BORNE PhD scholarship.

13. Brunton PJ. Neuroactive steroids and stress axis regulation: pregnancy and beyond. J Steroid Biochem Mol Biol (2016) 160:160-8. doi:10.1016/j. jsbmb.2015.08.003

14. Bowman ME, Lopata A, Jaffe RB, Golos TG, Wickings J, Smith R. Corticotropin-releasing hormone-binding protein in primates. $A m$ J Primatol (2001) 53:123-30. doi:10.1002/1098-2345(200103)53:3<123:: AID-AJP3>3.0.CO;2-V

15. Petraglia F, Sawchenko PE, Rivier J, Vale W. Evidence for local stimulation of ACTH secretion by corticotropin-releasing factor in human placenta. Nature (1987) 328:717-9. doi:10.1038/328717a0

16. Robinson BG, Arbiser JL, Emanuel RL, Majzoub JA. Species-specific placental corticotropin releasing hormone messenger RNA and peptide expression. Mol Cell Endocrinol (1989) 62:337-41. doi:10.1016/0303-7207(89)90022-1

17. Smith R, Wickings EJ, Bowman ME, Belleoud A, Dubreuil G, Davies JJ, et al. Corticotropin-releasing hormone in chimpanzee and gorilla pregnancies. J Clin Endocrinol Metab (1999) 84:2820-5. doi:10.1210/jcem.84.8.5906

18. Sandman CA, Glynn L, Schetter CD, Wadhwa P, Garite T, Chicz-DeMet A, et al. Elevated maternal cortisol early in pregnancy predicts third trimester levels of placental corticotropin releasing hormone (CRH): priming the placental clock. Peptides (2006) 27:1457-63. doi:10.1016/j.peptides.2005.10.002

19. Gomez-Roig MD, Mazarico E, Cardenas D, Fernandez MT, Diaz M, Ruiz de GB, et al. Placental 11B-hydroxysteroid dehydrogenase type 2 mRNA levels in intrauterine growth restriction versus small-for-gestational-age fetuses. Fetal Diagn Ther (2016) 39:147-51. doi:10.1159/000437139

20. Seckl JR, Meaney MJ. Glucocorticoid programming. Ann N Y Acad Sci (2004) 1032:63-84. doi:10.1196/annals.1314.006

21. Demendi C, Borzsonyi B, Pajor A, Rigo J Jr, Nagy ZB, Szentpeteri I, et al. Abnormal fetomaternal glucocorticoid metabolism in the background of premature delivery: placental expression patterns of the 11betahydroxysteroid dehydrogenase 2 gene. Eur J Obstet Gynecol Reprod Biol (2012) 165:210-4. doi:10.1016/j.ejogrb.2012.08.009

22. Seckl JR, Holmes MC. Mechanisms of disease: glucocorticoids, their placental metabolism and fetal 'programming' of adult pathophysiology. Nat Clin Pract Endocrinol Metab (2007) 3:479-88. doi:10.1038/ncpendmet0515

23. Weinstock M. The potential influence of maternal stress hormones on development and mental health of the offspring. Brain Behav Immun (2005) 19:296-308. doi:10.1016/j.bbi.2004.09.006

24. Davis EP, Head K, Buss C, Sandman CA. Prenatal maternal cortisolconcentrations predict neurodevelopment in middle childhood. Psychoneuroendocrinology (2017) 75:56-63. doi:10.1016/j.psyneuen.2016.10.005 
25. Perrone S, Santacroce A, Picardi A, Buonocore G. Fetal programming and early identification of newborns at high risk of free radical-mediated diseases. World J Clin Pediatr (2016) 5:172-81. doi:10.5409/wjcp.v5.i2.172

26. Alexander BT, Dasinger JH, Intapad S. Fetal programming and cardiovascular pathology. Compr Physiol (2015) 5:997-1025. doi:10.1002/cphy. c140036

27. Brunton PJ, Russell JA, Douglas AJ. Adaptive responses of the maternal hypothalamic-pituitary-adrenal axis during pregnancy and lactation. J Neuroendocrinol (2008) 20:764-76. doi:10.1111/j.1365-2826.2008.01735.x

28. de Weerth C, Buitelaar JK. Physiological stress reactivity in human pregnancy-a review. Neurosci Biobehav Rev (2005) 29:295-312. doi:10.1016/j. neubiorev.2004.10.005

29. Kammerer M, Adams D, Castelberg Bv BV, Glover V. Pregnant women become insensitive to cold stress. BMC Pregnancy Childbirth (2002) 2:8. doi:10.1186/1471-2393-2-8

30. Schulte HM, Weisner D, Allolio B. The corticotrophin releasing hormone test in late pregnancy: lack of adrenocorticotrophin and cortisol response. Clin Endocrinol (Oxf) (1990) 33:99-106. doi:10.1111/j.1365-2265.1990. tb00470.x

31. Dunkel SC, Tanner L. Anxiety, depression and stress in pregnancy: implications for mothers, children, research, and practice. Curr Opin Psychiatry (2012) 25:141-8. doi:10.1097/YCO.0b013e3283503680

32. Glynn LM, Schetter CD, Hobel CJ, Sandman CA. Pattern of perceived stress and anxiety in pregnancy predicts preterm birth. Health Psychol (2008) 27:43-51. doi:10.1037/0278-6133.27.1.43

33. Shapiro GD, Fraser WD, Frasch MG, Seguin JR. Psychosocial stress in pregnancy and preterm birth: associations and mechanisms. J Perinat Med (2013) 41:631-45. doi:10.1515/jpm-2012-0295

34. Magiakou MA, Mastorakos G, Rabin D, Dubbert B, Gold PW, Chrousos GP. Hypothalamic corticotropin-releasing hormone suppression during the postpartum period: implications for the increase in psychiatric manifestations at this time. J Clin Endocrinol Metab (1996) 81:1912-7. doi:10.1210/ jcem.81.5.8626857

35. Owens PC, Smith R, Brinsmead MW, Hall C, Rowley M, Hurt D, et al. Postnatal disappearance of the pregnancy-associated reduced sensitivity of plasma cortisol to feedback inhibition. Life Sci (1987) 41:1745-50.

36. Bosch OJ, Musch W, Bredewold R, Slattery DA, Neumann ID. Prenatal stress increases HPA axis activity and impairs maternal care in lactating female offspring: implications for postpartum mood disorder. Psychoneuroendocrinology (2007) 32:267-78. doi:10.1016/j.psyneuen.2006. 12.012

37. Brunton PJ. Effects of maternal exposure to social stress during pregnancy: consequences for mother and offspring. Reproduction (2013) 146:R175-89. doi:10.1530/REP-13-0258

38. Bellisario V, Panetta P, Balsevich G, Baumann V, Noble J, Raggi C, et al. Maternal high-fat diet acts as a stressor increasing maternal glucocorticoids' signaling to the fetus and disrupting maternal behavior and brain activation in C57BL/6J mice. Psychoneuroendocrinology (2015) 60:138-50. doi:10.1016/j.psyneuen.2015.06.012

39. Brunton PJ, Russell JA. The expectant brain: adapting for motherhood. Nat Rev Neurosci (2008) 9:11-25. doi:10.1038/nrn2280

40. Ladyman SR. Leptin resistance during pregnancy in the rat. J Neuroendocrinol (2008) 20:269-77. doi:10.1111/j.1365-2826.2007.01628.x

41. Pedersen J. Diabetes mellitus and pregnancy: present status of the hyperglycaemia - hyperinsulinism theory and the weight of the newborn baby. Postgrad Med J (1971) (Suppl):66-7.

42. Barker DJ, Gluckman PD, Godfrey KM, Harding JE, Owens JA, Robinson JS. Fetal nutrition and cardiovascular disease in adult life. Lancet (1993) 341:938-41. doi:10.1016/0140-6736(93)91224-A

43. Entringer S. Impact of stress and stress physiology during pregnancy on child metabolic function and obesity risk. Curr Opin Clin Nutr Metab Care (2013) 16:320-7. doi:10.1097/MCO.0b013e32835e8d80

44. Paternain L, de la Garza AL, Batlle MA, Milagro FI, Martinez JA, Campion J. Prenatal stress increases the obesogenic effects of a highfat-sucrose diet in adult rats in a sex-specific manner. Stress (2013) 16:220-32. doi:10.3109/10253890.2012.707708

45. Tamashiro KL, Terrillion CE, Hyun J, Koenig JI, Moran TH. Prenatal stress or high-fat diet increases susceptibility to diet-induced obesity in rat offspring. Diabetes (2009) 58:1116-25. doi:10.2337/db08-1129
46. Marciniak A, Patro-Malysza J, Kimber-Trojnar Z, Marciniak B, Oleszczuk J, Leszczynska-Gorzelak B. Fetal programming of the metabolic syndrome. Taiwan J Obstet Gynecol (2017) 56:133-8. doi:10.1016/j. tjog.2017.01.001

47. Bouret SG. Early life origins of obesity: role of hypothalamic programming. J Pediatr Gastroenterol Nutr (2009) 48(Suppl 1):S31-8. doi:10.1097/ MPG.0b013e3181977375

48. MacKay H, Abizaid A. Embryonic development of the hypothalamic feeding circuitry: transcriptional, nutritional, and hormonal influences. Mol Metab (2014) 3:813-22. doi:10.1016/j.molmet.2014.09.004

49. Zambrano E, Ibanez C, Martinez-Samayoa PM, Lomas-Soria C, DurandCarbajal M, Rodriguez-Gonzalez GL. Maternal obesity: lifelong metabolic outcomes for offspring from poor developmental trajectories during the perinatal period. Arch Med Res (2016) 47:1-12. doi:10.1016/j.arcmed.2016.01.004

50. Kensara OA, Wootton SA, Phillips DI, Patel M, Jackson AA, Elia M. Fetal programming of body composition: relation between birth weight and body composition measured with dual-energy X-ray absorptiometry and anthropometric methods in older Englishmen. Am J Clin Nutr (2005) 82:980-7.

51. Stout SA, Espel EV, Sandman CA, Glynn LM, Davis EP. Fetal programming of children's obesity risk. Psychoneuroendocrinology (2015) 53:29-39. doi:10.1016/j.psyneuen.2014.12.009

52. Ibanez L, Ong K, Dunger DB, de ZF. Early development of adiposity and insulin resistance after catch-up weight gain in small-for-gestational-age children. J Clin Endocrinol Metab (2006) 91:2153-8. doi:10.1210/jc.2005-2778

53. Gillman MW, Rich-Edwards JW, Huh S, Majzoub JA, Oken E, Taveras EM, et al. Maternal corticotropin-releasing hormone levels during pregnancy and offspring adiposity. Obesity (Silver Spring) (2006) 14:1647-53. doi:10.1038/ oby.2006.189

54. Fasting MH, Oken E, Mantzoros CS, Rich-Edwards JW, Majzoub JA, Kleinman K, et al. Maternal levels of corticotropin-releasing hormone during pregnancy in relation to adiponectin and leptin in early childhood. J Clin Endocrinol Metab (2009) 94:1409-15. doi:10.1210/jc.2008-1424

55. Mingrone G, Manco M, Mora ME, Guidone C, Iaconelli A, Gniuli D, et al. Influence of maternal obesity on insulin sensitivity and secretion in offspring. Diabetes Care (2008) 31:1872-6. doi:10.2337/dc08-0432

56. Whitaker RC. Predicting preschooler obesity at birth: the role of maternal obesity in early pregnancy. Pediatrics (2004) 114:e29-36. doi:10.1542/ peds.114.1.e29

57. Maffeis C, Morandi A. Effect of maternal obesity on foetal growth and metabolic health of the offspring. Obes Facts (2017) 10:112-7. doi:10.1159/000456668

58. Gao L, Lv C, Xu C, Li Y, Cui X, Gu H, et al. Differential regulation of glucose transporters mediated by CRH receptor type 1 and type 2 in human placental trophoblasts. Endocrinology (2012) 153:1464-71. doi:10.1210/en.2011-1673

59. Briana DD, Malamitsi-Puchner A. Reviews: adipocytokines in normal and complicated pregnancies. Reprod Sci (2009) 16:921-37. doi:10.1177/1933719109336614

60. Wadhwa PD, Garite TJ, Porto M, Glynn L, Chicz-DeMet A, Dunkel-Schetter C, et al. Placental corticotropin-releasing hormone $(\mathrm{CRH})$, spontaneous preterm birth, and fetal growth restriction: a prospective investigation. Am J Obstet Gynecol (2004) 191:1063-9. doi:10.1016/j.ajog.2004.06.070

61. Whitehead CL, Walker SP, Ye L, Mendis S, Kaitu'u-Lino TJ, Lappas M, et al. Placental specific mRNA in the maternal circulation are globally dysregulated in pregnancies complicated by fetal growth restriction. J Clin Endocrinol Metab (2013) 98:E429-36. doi:10.1210/jc.2012-2468

62. Lockwood CJ, Kuczynski E. Markers of risk for preterm delivery. J Perinat Med (1999) 27:5-20. doi:10.1515/JPM.1999.001

63. Wolfe CD, Patel SP, Linton EA, Campbell EA, Anderson J, Dornhorst A, et al. Plasma corticotrophin-releasing factor (CRF) in abnormal pregnancy. Br JObstet Gynaecol (1988) 95:1003-6. doi:10.1111/j.1471-0528.1988. tb06504.x

64. Clifton VL, Read MA, Leitch IM, Boura AL, Robinson PJ, Smith R. Corticotropin-releasing hormone-induced vasodilatation in the human fetal placental circulation. J Clin Endocrinol Metab (1994) 79:666-9. doi:10.1210/ jcem.79.2.8045990

65. Harville EW, Savitz DA, Dole N, Herring AH, Thorp JM, Light KC. Stress and placental resistance measured by Doppler ultrasound in early and mid-pregnancy. Ultrasound Obstet Gynecol (2008) 32:23-30. doi:10.1002/ uog. 5344 
66. Choy MY, Leung TN, Lau TK. Corticotropin-releasing hormone peptide and human first-trimester placental growth. Early Hum Dev (2004) 79:77-80. doi:10.1016/j.earlhumdev.2004.04.010

67. Wakahashi S, Nakabayashi K, Maruo N, Yata A, Ohara N, Maruo T. Effects of corticotropin-releasing hormone and stresscopin on vascular endothelial growth factor mRNA expression in cultured early human extravillous trophoblasts. Endocrine (2008) 33:144-51. doi:10.1007/s12020-008-9071-0

68. McLean M, Bisits A, Davies J, Woods R, Lowry P, Smith R. A placental clock controlling the length of human pregnancy. Nat Med (1995) 1:460-3. doi:10.1038/nm0595-460

69. Grammatopoulos DK. The role of CRH receptors and their agonists in myometrial contractility and quiescence during pregnancy and labour. Front Biosci (2007) 12:561-71. doi:10.2741/2082

70. Class QA, Buss C, Davis EP, Gierczak M, Pattillo C, Chicz-DeMet A, et al. Low levels of corticotropin-releasing hormone during early pregnancy are associated with precocious maturation of the human fetus. Dev Neurosci (2008) 30:419-26. doi:10.1159/000191213

71. Ellman LM, Schetter CD, Hobel CJ, Chicz-DeMet A, Glynn LM, Sandman CA. Timing of fetal exposure to stress hormones: effects on newborn physical and neuromuscular maturation. Dev Psychobiol (2008) 50:232-41. doi:10.1002/dev.20293

72. Sandman CA, Davis EP, Buss C, Glynn LM. Prenatal programming of human neurological function. Int JPept (2011) 2011:837596. doi:10.1155/2011/837596

73. Baram TZ, Hatalski CG. Neuropeptide-mediated excitability: a key triggering mechanism for seizure generation in the developing brain. Trends Neurosci (1998) 21:471-6. doi:10.1016/S0166-2236(98)01275-2

74. Brunson KL, Chen Y, Avishai-Eliner S, Baram TZ. Stress and the developing hippocampus: a double-edged sword? Mol Neurobiol (2003) 27:121-36. doi:10.1385/MN:27:2:121

75. Hollrigel GS, Chen K, Baram TZ, Soltesz I. The pro-convulsant actions of corticotropin-releasing hormone in the hippocampus of infant rats. Neuroscience (1998) 84:71-9. doi:10.1016/S0306-4522(97)00499-5

76. Ehlers CL, Henriksen SJ, Wang M, Rivier J, Vale W, Bloom FE. Corticotropin releasing factor produces increases in brain excitability and convulsive seizures in rats. Brain Res (1983) 278:332-6. doi:10.1016/0006-8993(83)90266-4

77. Korosi A, Baram TZ. The central corticotropin releasing factor system during development and adulthood. Eur J Pharmacol (2008) 583:204-14. doi:10.1016/j.ejphar.2007.11.066

78. Pihoker C, Owens MJ, Kuhn CM, Schanberg SM, Nemeroff CB. Maternal separation in neonatal rats elicits activation of the hypothalamicpituitary-adrenocortical axis: a putative role for corticotropin-releasing factor. Psychoneuroendocrinology (1993) 18:485-93. doi:10.1016/0306-4530 (93) $90042-\mathrm{J}$

79. Weaver IC. Shaping adult phenotypes through early life environments. Birth Defects Res C Embryo Today (2009) 87:314-26. doi:10.1002/bdrc.20164

80. Faturi CB, Tiba PA, Kawakami SE, Catallani B, Kerstens M, Suchecki D. Disruptions of the mother-infant relationship and stress-related behaviours: altered corticosterone secretion does not explain everything. Neurosci Biobehav Rev (2010) 34:821-34. doi:10.1016/j.neubiorev.2009.09.002

81. Schmidt MV. Molecular mechanisms of early life stress - lessons from mouse models. Neurosci Biobehav Rev (2010) 34:845-52. doi:10.1016/j. neubiorev.2009.05.002

82. Walker CD, Tankosic P, Tilders FJ, Burlet A. Immunotargeted lesions of paraventricular CRF and AVP neurons in developing rats reveal the pattern of maturation of these systems and their functional importance. J Neuroendocrinol (1997) 9:25-41. doi:10.1046/j.1365-2826.1997.00544.x

83. van Bodegom M, Homberg JR, Henckens MJAG. Modulation of the hypothalamic-pituitary-adrenal axis by early life stress exposure. Front Cell Neurosci (2017) 11:87. doi:10.3389/fncel.2017.00087

84. Gunnar MR, Donzella B. Social regulation of the cortisol levels in early human development. Psychoneuroendocrinology (2002) 27:199-220. doi:10.1016/S0306-4530(01)00045-2

85. Sanchez MM, McCormack KM, Howell BR. Social buffering of stress responses in nonhuman primates: maternal regulation of the development of emotional regulatory brain circuits. Soc Neurosci (2015) 10:512-26. doi:10.1080/17470919.2015.1087426

86. Brummelte S, Schmidt KL, Taves MD, Soma KK, Galea LA. Elevated corticosterone levels in stomach milk, serum, and brain of male and female offspring after maternal corticosterone treatment in the rat. Dev Neurobiol (2010) 70:714-25. doi:10.1002/dneu.20805

87. Benjamin Neelon SE, Stroo M, Mayhew M, Maselko J, Hoyo C. Correlation between maternal and infant cortisol varies by breastfeeding status. Infant Behav Dev (2015) 40:252-8. doi:10.1016/j.infbeh.2015.06.005

88. Vazquez DM, Neal CR Jr, Patel PD, Kaciroti N, Lopez JF. Regulation of corticoid and serotonin receptor brain system following early life exposure of glucocorticoids: long term implications for the neurobiology of mood. Psychoneuroendocrinology (2012) 37:421-37. doi:10.1016/j.psyneuen. 2011.07.012

89. Desai M, Jellyman JK, Han G, Beall M, Lane RH, Ross MG. Maternal obesity and high-fat diet program offspring metabolic syndrome. Am JObstet Gynecol (2014) 211:237. doi:10.1016/j.ajog.2014.03.025

90. Maniam J, Antoniadis C, Morris MJ. Early-life stress, HPA axis adaptation, and mechanisms contributing to later health outcomes. Front Endocrinol (2014) 5:73. doi:10.3389/fendo.2014.00073

91. Weaver IC, Cervoni N, Champagne FA, D’Alessio AC, Sharma S, Seckl JR, et al. Epigenetic programming by maternal behavior. Nat Neurosci (2004) 7:847-54. doi:10.1038/nn1276

92. Fenoglio KA, Brunson KL, Avishai-Eliner S, Stone BA, Kapadia BJ, Baram TZ. Enduring, handling-evoked enhancement of hippocampal memory function and glucocorticoid receptor expression involves activation of the corticotropin-releasing factor type 1 receptor. Endocrinology (2005) 146:4090-6. doi:10.1210/en.2004-1285

93. Suderman M, McGowan PO, Sasaki A, Huang TC, Hallett MT, Meaney MJ, et al. Conserved epigenetic sensitivity to early life experience in the rat and human hippocampus. Proc Natl Acad Sci U S A (2012) 109(Suppl 2):17266-72. doi:10.1073/pnas.1121260109

94. Romens SE, McDonald J, Svaren J, Pollak SD. Associations between early life stress and gene methylation in children. Child Dev (2015) 86:303-9. doi:10.1111/cdev.12270

95. Labonte B, Yerko V, Gross J, Mechawar N, Meaney MJ, Szyf M, et al. Differential glucocorticoid receptor exon $1(\mathrm{~B}), 1(\mathrm{C})$, and $1(\mathrm{H})$ expression and methylation in suicide completers with a history of childhood abuse. Biol Psychiatry (2012) 72:41-8. doi:10.1016/j.biopsych.2012.01.034

96. Chen J, Evans AN, Liu Y, Honda M, Saavedra JM, Aguilera G. Maternal deprivation in rats is associated with corticotrophin-releasing hormone (CRH) promoter hypomethylation and enhances CRH transcriptional responses to stress in adulthood. J Neuroendocrinol (2012) 24:1055-64. doi:10.1111/j.1365-2826.2012.02306.x

97. Wang A, Nie W, Li H, Hou Y, Yu Z, Fan Q, et al. Epigenetic upregulation of corticotrophin-releasing hormone mediates postnatal maternal separationinduced memory deficiency. PLoS One (2014) 9:e94394. doi:10.1371/journal. pone.0094394

98. Singh-Taylor A, Molet J, Jiang S, Korosi A, Bolton JL, Noam Y, et al. NRSFdependent epigenetic mechanisms contribute to programming of stresssensitive neurons by neonatal experience, promoting resilience. Mol Psychiatry (2017). doi:10.1038/mp.2016.240

99. Eghbal-Ahmadi M, Avishai-Eliner S, Hatalski CG, Baram TZ. Differential regulation of the expression of corticotropin-releasing factor receptor type 2 (CRF2) in hypothalamus and amygdala of the immature rat by sensory input and food intake. J Neurosci (1999) 19:3982-91.

100. Pelleymounter MA, Joppa M, Ling N, Foster AC. Pharmacological evidence supporting a role for central corticotropin-releasing factor(2) receptors in behavioral, but not endocrine, response to environmental stress. J Pharmacol Exp Ther (2002) 302:145-52. doi:10.1124/jpet.302.1.145

101. D’Amato FR, Cabib S, Puglisi-Allegra S, Patacchioli FR, Cigliana G, Maccari S, et al. Effects of acute and repeated exposure to stress on the hypothalamo-pituitary-adrenocortical activity in mice during postnatal development. Horm Behav (1992) 26:474-85. doi:10.1016/0018-506X(92) 90015-N

102. Yam KY, Naninck EF, Schmidt MV, Lucassen PJ, Korosi A. Early-life adversity programs emotional functions and the neuroendocrine stress system: the contribution of nutrition, metabolic hormones and epigenetic mechanisms. Stress (2015) 18:328-42. doi:10.3109/10253890.2015.1064890

103. Plotsky PM, Meaney MJ. Early, postnatal experience alters hypothalamic corticotropin-releasing factor (CRF) mRNA, median eminence CRF content and stress-induced release in adult rats. Brain Res Mol Brain Res (1993) 18:195-200. doi:10.1016/0169-328X(93)90189-V 
104. Arborelius L, Owens MJ, Plotsky PM, Nemeroff CB. The role of corticotropin-releasing factor in depression and anxiety disorders. J Endocrinol (1999) 160:1-12. doi:10.1677/joe.0.1600001

105. Chen Y, Baram TZ. Toward understanding how early-life stress reprograms cognitive and emotional brain networks. Neuropsychopharmacology (2016) 41:197-206. doi:10.1038/npp.2015.181

106. Machado TD, Dalle MR, Laureano DP, Portella AK, Werlang IC, Benetti CS, et al. Early life stress is associated with anxiety, increased stress responsivity and preference for "comfort foods" in adult female rats. Stress (2013) 16: 549-56. doi:10.3109/10253890.2013.816841

107. Husum H, Mathe AA. Early life stress changes concentrations of neuropeptide $\mathrm{Y}$ and corticotropin-releasing hormone in adult rat brain. Lithium treatment modifies these changes. Neuropsychopharmacology (2002) 27:756-64. doi:10.1016/S0893-133X(02)00363-9

108. Alcantara-Alonso V, Amaya MI, Matamoros-Trejo G, de Gortari P. Altered functionality of the corticotrophin-releasing hormone receptor-2 in the hypothalamic paraventricular nucleus of hyperphagic maternally separated rats. Neuropeptides (2017) 63:75-82. doi:10.1016/j.npep.2017. 01.006

109. Peng H, Long Y, Li J, Guo Y, Wu H, Yang Y, et al. Hypothalamic-pituitaryadrenal axis functioning and dysfunctional attitude in depressed patients with and without childhood neglect. BMC Psychiatry (2014) 14:45. doi:10.1186/1471-244X-14-45

110. Lee R, Geracioti TD Jr, Kasckow JW, Coccaro EF. Childhood trauma and personality disorder: positive correlation with adult CSF corticotropin-releasing factor concentrations. Am J Psychiatry (2005) 162:995-7. doi:10.1176/appi.ajp.162.5.995
111. Turecki G, Meaney MJ. Effects of the social environment and stress on glucocorticoid receptor gene methylation: a systematic review. Biol Psychiatry (2016) 79:87-96. doi:10.1016/j.biopsych.2014.11.022

112. Dallman MF. Stress-induced obesity and the emotional nervous system. Trends Endocrinol Metab (2010) 21:159-65. doi:10.1016/j.tem.2009.10.004

113. Pasquali R. The hypothalamic-pituitary-adrenal axis and sex hormones in chronic stress and obesity: pathophysiological and clinical aspects. Ann N Y Acad Sci (2012) 1264:20-35. doi:10.1111/j.1749-6632.2012.06569.x

114. Larsen PJ, Jessop DS, Chowdrey HS, Lightman SL, Mikkelsen JD. Chronic administration of glucocorticoids directly upregulates preproneuropeptide Y and Y1-receptor mRNA levels in the arcuate nucleus of the rat. JNeuroendocrinol (1994) 6:153-9. doi:10.1111/j.1365-2826.1994. tb00566.x

115. Pervanidou P, Chrousos GP. Metabolic consequences of stress during childhood and adolescence. Metabolism (2012) 61:611-9. doi:10.1016/j. metabol.2012.01.014

Conflict of Interest Statement: The authors declare absence of any commercial or financial relationship that could be construed as a potential conflict of interest.

Copyright (C) 2017 Alcántara-Alonso, Panetta, de Gortari and Grammatopoulos. This is an open-access article distributed under the terms of the Creative Commons Attribution License (CC BY). The use, distribution or reproduction in other forums is permitted, provided the original author(s) or licensor are credited and that the original publication in this journal is cited, in accordance with accepted academic practice. No use, distribution or reproduction is permitted which does not comply with these terms. 